\author{
Arnoldo José GABALDÓN
}

Andrés Bello Catholic University

\title{
ENVIRONMENTAL CHALLENGES \\ OF AN OIL-RENT BASED ECONOMY
}

ABSTRACT This paper addresses the environmental issues taking place in Venezuela an oil rent-based economy and a mono-producing country. This article reports on the transformations that occurred during the last ninety years since oil exploration began. The development style of a mono-producing country has had direct consequences in terms of the generated social and environmental impacts. But also, in terms of a number of other issues that have affected the relationship between society and nature and that has given very specific characteristics to that relationship. In consequence, the current environmental management must face a series of challenges. This paper proposes the outline of the environmental strategy that must be followed: a more challenging environmental management of oil industry; improvement of urban environmental management; sustainable management of water resources; biodiversity conservation; and sustainable development education. In conclusion it formulates some ideas that revile the most important lessons from the Venezuelan experience regarding environmental management.

KEY WORDS Environmental politics, natural resources, oil economy, Venezuela.

\section{INTRODUCTION}

To talk about Venezuela and not mention the existential relationship established during its recent history, among the use of its oil wealth and the realization of the social, economic and political activities, would be a serious omission, to say the least. This 
would be an even more serious case of neglect, as Venezuela acknowledged over the last century the connotation between the mono-producing and the oil revenue-based economy.

I have been asked to address the Venezuelan environmental problems in this article, and I considered it obvious to talk about the challenges of natural resources conservation for an oil mono-producing country.

This paper explains how the country turned into an oil revenue-based economy through its social and historical development during the last nine decades of its existence. And then, it goes on to describe what the most relevant social and environmental impacts of the oil industry in Venezuela have been. It also explains other results of the environmental impact associated with the development style of a mono-producing country and, finally, present what the main challenges of environmental management in Venezuela are.

\section{VENEZUELA: A MONO-PRODUCING COUNTRY}

Venezuela was a very backward and poor country until the first quarter of the twentieth century. By 1920 , only $21.5 \%$ of its total population, 2.363 .0000 inhabitants ${ }^{1}$, was considered urban, being mostly illiterate and suffering from very poor health conditions, which meant that life expectancy at birth was under 40 years. Its economy depended on the high share of agriculture and its main export goods were coffee and cocoa.

During the 1920s a large-scale exploitation of Venezuela'svast oil wealth was initiated by transnational companies. While it could said that, from the beginning of this new phase of its evolution, hydrocarbon exploitation endowed the country with the amount of money it had never seen before, there also were thinkers who were concerned about the inconvenience of allowing the economy to be dependent exclusively on one thing and the income tax it generated. As it was also the exploitation of a natural resource that was not renewable, they voiced numerous alerts concerning the need of allocating oil revenues for productive investment in agriculture and industry, which would allow for the diversification of the economy and would place it on a more sustainable foundation. Thus, it emerged as national development guideline for all subsequent governments: The planting of oil. A motto with ecological roots, since that date, has been flogging the national soul, reminding of their inconsistency or inability to achieve through consensus and public policy the diversification of the economy.

For almost a hundred years since the beginning of the oil era, Venezuela has significantly modernized and improved the health and education of its population. By 2010, the life expectancy of its population rose to 73 years, and illiteracy was reduced to a minimum. The counrty has an extensive road network. Last year the population was close to 30 million. However, the country's economy still depends heavily on the oil industry.

República Bolivariana de Venezuela. Censos Nacionales de Poblacion. Instituto Nacional deEstadísticas, 2006. 
For 2008, 80\% of its exports were oil or its derivatives, and income tax was dependent on oil in $45 \%$. Therefore, its macroeconomic stability was strongly tied to the swing in oil prices in international markets. This led Venezuela to be properly classified as a mono-producing and oil rent-based economy caounrty.

Therefore, the status as a hydrocarbon mono-producing country puts us in a special category when attempting to address our environmental problems, as explained below.

\section{SOCIO-ENVIRONMENTAL IMPACT OF OIL INDUSTRY, ALONG THE HISTORY OF VENEZUELA}

As soon as oil exploration was commenced on the shores of Maracaibo Lake, there began to occur spills that polluted the water. At first, it was done without constraint, because the lake bottom had places where mineral oil would flow freely. Moreover, when some fishermen realized the scale of the phenomenon that was happening, and its harmful effects on the wildlife of Lacustrina, they began to voice their justified protests. This social reaction echoed in Congress and, despite the scant democratic and ecological awareness of its members, its members were forced to legislate against the interests of foreign corporations that extracted oil. In 1928, the first law of vigilance was passed to prevent pollution of the waters of the Lake from oil, in what was probably the country's pioneering legal instrument on environmental. ${ }^{2}$

The oil industry, by its nature, is highly degrading to the environment. The impacts on the physical and natural environment does not only occur in the areas of exploration and production, which usually affect the landscape dramatically, but also involves oil pipes and gas transport that reaches most of the territory, as well as processing points, shipping and distribution facilities. But beyond these effects on the natural ecology, there are also important social and environmental effects. In an impoverished society oil industry creatednew job opportunities typical of capital-intensive projects, generated strong internal migration which caused major imbalances in agricultural workforce source, but also created even worse living conditions in human settlements that grew haphazardly around the oil fields.

ARA Network ${ }^{3}$, a consortium of environmental NGOs in Venezuela, has listed the main environmental problems generated by the oil industry throughout its history. A summary of the situation is the following:

- Damage to ecosystems where oil exploration has concentrated, especially in the Maracaibo Lake basin and in the eastern states of Anzoategui and Monagas, with serious consequences to biodiversity, soil and water. The Lake, as freshwater ecosystem, the largest one in South America, has suffered greatly from the

A.J. Gabaldon, 'De aire puro si vive el hombre: ambiente y desarrollo' in A. Baptista (coord.), Venezuela Siglo XX. Visiones y Testimonios, Tomo 3, Caracas 2001.

3 Red ARA, Aportes para un diagnostico de la problemática ambiental de Venezuela. La visión de la Red ARA, Caracas 2011, pp. 26-27. 
constant oil spills and leaks that have occurred and continue to occur within and along its banks.

- Presence of an extensive range of environmental liabilities accrued in operating areas and sometimes in the oil-ducts corridors, including oil waste pits at risk of flooding and leaching. The natural landscapes have been severely degraded. Around 10,000 oil pools have been identified across the country, including large volumes of hazardous wastes including drilling mud and numerous brown fields.

- In areas that have concentrated hydrocarbon processing, such as the east bank of Maracaibo Lake, which houses - among other facilities - the petrochemical complex of El Tablazo in Paraguana Peninsula, which includes the two largest refineries in the country, the Cardón and Amuay, and the Jose petrochemical complex in Anzoategui state, which generates all the environmental problems of large-scale industrial oil plants: release of huge volumes of waste, failures in the management of products derived from the refining process (mainly sulfur and coke) which cause pollution of water, air and soil, high volumes of emissions to the atmosphere of $\mathrm{CO} 2, \mathrm{SO} 2$ and $\mathrm{NOx}$ from the processes of refining and improving, discharge of petroleum products into water bodies and soil, faulty product control processes, maintenance and prevention. In 2012, a blowout of an oil pipeline in Jusepín, Monagas state, caused the pollution of Guarapiche River. This river is the main source of supply of the aqueduct of Maturin City, the state capital, with a population of nearly 600,000 . For these reasons, the city had to suffer almost total disruption of drinking water supply for over 40 days, with the attendant social and economic problems.

- The main front of exploration, production and processing of oil today is located in the Orinoco Oil Belt, a huge oil-heavy reservoir. The use of this type of oil generates strong environmental impact, given the residue of coke and other minerals produced, high water demands, and the strong intervention into the landscape.

- High environmental and social risks associated with the development of oil and gas mega-projects in their areas of influence.

The above are the direct environmental footprints, more evident of the oil industry, but there are many other forms of environmental degradation that are linked obliquely to the same activities. This is the case, for example, with the impact on the environment caused by pollutants in the atmosphere generated by a highly energized economy, and providing fuel whose prices are heavily subsidized. For these same reasons - and others linked to the nature of the country's oil economy, in which the abundance of foreign exchange has allowed for the import of all types of motor vehicles - there are now countless fleet of vehicles that constitute the main cause of pollution the air of the cities. Likewise, the availability of very cheap fossil fuels has meant a discouragement for energy efficiency, thus contributing to the depletion of nonrenewable capital, as well as other phenomena to the same effect. 


\section{OTHER ENVIRONMENTAL IMPACTS ASSOCIATED WITH THE DEVELOPMENT OF A MONO-PRODUCING COUNTRY}

It would be true to say that all environmental problems affecting Venezuela today are caused by the oil industry. But we must consider that the development styles adopted by countries have profound influence on how they form their relationship with society and nature.

Venezuela adopted, from the second decade of the twentieth century, the development of an oil mono-producing style, and its society established a special relationship with its natural environment. Three aspects are often relevant from that perspective. First, the extraction activities of materials and energy from nature, as well as the transformation, accumulation and consumption of said resources; second, the generation of waste and scrap returning to the biosphere; and third, the territorial layout that these activities ${ }^{4}$ involve. That is why sometimes we do not realize that under a series of events that degrade the environment, there lies the particular style of development adopted. Next, we comment on a number of major environmental problems affecting Venezuela and, as has been said, those are strongly linked to the development of the oil mono-producing style.

\section{The urban environmental problems}

Oil rents are paid and administered by the state and spent or invested preferably in the towns where they are unmet social demands; as such, they served as a powerful magnet for the rural population, giving rise to a rapid urbanization process. In the sixty years from 1920-1980, the percentage of urban population was reversed, from $21.5 \%$ to $80.0 \%$ and the total population increased almost fourfold, thanks to the success of the health policy, achieved through the vision of its drivers and the amount of oil revenues allocated to it. By 2010 , the $87 \%$ of the total population lived in cities with more than 2500 inhabitants. This very rapid urbanization has resulted in considerable degradation of environmental conditions in most of the major population centers due to the financial and institutional incapacity of the country to organize urban growth. As a result, it has decreased the quality of life of its inhabitants.

Environmental factors that have contributed to this phenomenon and that often impacted on the health of the population are several: a) a deficiency of drinking water and sanitation, especially in neighborhoods inhabited by the poor population, which sometimes does not enjoy a continuous supply or water quality is not assured; b) the collection and proper disposal of urban waste is deficient in a number of population groups. The health and aesthetic implications of this problem are very broad.

4 O. Sunkel, N. Gliko (selección), Estilos de Desarollo y Medio Ambiente en América Latina, Tomo 1-2, Caracas 1972. 
Rapid urbanization has occurred especially in large and medium towns, has been advanced without much planning, with deficient roads systems, commonly causing congestion and the lack of provision of adequate social spaces and green areas.

\section{The water pollution}

Venezuela has abundant water resources in terms of its population and activities. However, the geographic location of the population with respect to the territorial distribution of water creates serious imbalances to be resolved with the investment of financial and technical resources. Indeed, $93 \%$ of the population is settled on the left bank of the main river, the Orinoco, especially in the northern coastal strip, which has only a very small percentage (less than 10\%) of the total availability of the country's water. For these reasons, the water supply of the population and economic activities is difficult. Water scarcity is exacerbated by progressive contamination in areas of human settlement and also in the periphery of agricultural areas. As a result, it is difficult to find fluvial stream or water bodies that do not have some level of contamination. Moreover, a high percentage of the Venezuelan beaches in the Caribbean Sea are contaminated and therefore should not be used for tourism and recreation.

\section{The destruction of terrestrial and marine biodiversity}

From the beginning of the oil era, Venezuela started a period of major interventions on the natural landscape. The Andean foothills and high plains were included as areas for agriculture, and the occupation of large areas of flat topography in the high plains, where health campaigns had triumphed over malaria, allowing the development of a more technologically advanced agriculture. This occupation was marked by the construction of infrastructure, opening of new water and drainages channels, deforestation of large areas to expand the agricultural frontier and the disruption of natural drainage networks, among other things. As a result, the attack on biodiversity has been strong. It includes the intervention or destruction of natural habitats for many species of fauna and flora, land, and water.

\section{The energy waste}

The abundance and low prices of fossil fuels have led to the misuse of the energy potential. This misuse is evident in the way is organized the transport sector is organized for instance, as it is largely dependent on motor vehicles, where private cars are the preferred means; or electricity generation based on thermoelectric plants. Fortunately there have been visionary minds that, despite the wealth of fossil fuels, pushed for the development of hydro-power plants and now these primary energy sources meet about $70 \%$ of the electricity demand. Besides the waste of non-renewable natural resources, another consequence of the situation described above has been the increasing pollution with $\mathrm{CO} 2, \mathrm{SO} 2$ and $\mathrm{NOx}$, especially in urban environments. 


\section{THE CHALLENGES OF ENVIRONMENTAL MANAGEMENT IN VENEZUELA}

Now, in view of the framework described above, what are the priority actions to be taken in order to advance sustainable environmental management?

\section{A. A more demanding oil environmental management}

The energy transition is happening in the world, fueled in part by fear of the consequences of the climate change, a phenomenon that will not affect Venezuela immediately, and possibly not in the medium term, either. The volume of hydrocarbon reserves available in the country and the speed of the previous process, create scenarios in which that oil will continue to play a very important role in the Venezuelan economy, at least two or three decades.

For the reasons, from an ecological perspective, it is very important to give greater relevance to the environmental management of the oil industry. In the past, the oil industry developed an acceptable management. It established units for health, safety and environment, on every front of numerous activities and prepared contingency plans for various accidents and especially oil spills. It so happens, however, that during the last decade the prevention mechanisms have become more lax, to say the least, and timely response is difficult when facing to environmental damage and serious environmental accidents that nowadays frequently take place in our refineries, pipelines and other facilities.

As discussed earlier, the oil industry is responsible for a wide range of environmental impact factors. It is therefore necessary to review both the management structures responsible for environmental management, as well as their procedures and technologies, adopting the edge technologies that are in constant development and the establishment of regular audits, to record the efficiency and effectiveness of actions implemented in the environmental area.

\section{B. Improve urban environmental management}

Environmental improvement of urban environment would, generate great benefits for the majority of Venezuelans in terms of quality of life. Now, what could be included in such improvement programs?

- Modernizing solid waste management, an area in which there are serious deficiencies. A Comprehensive Waste Management Act was recently passed ${ }^{5}$. Its implementation will require planners and supervisors develop structures at the central, state and municipal levels, training specialized technical and administrative staff and investing significant financial resources to provide all municipalities or municipal bodies with equipment, infrastructure and mechanical installations required, among other initiatives. The goal is to clean cities based 
on a good house and collection service, where streets and avenues are swept and trash is collected and disposed of, according to technical and health criteria.

- Improve water services so that it can be uninterrupted and have the required quality. This is especially necessary in neighborhoods where mostly poor people live. Equally supply urban sanitation services to all homes and connect them to sewage networks; sewage must and receive proper effluent treatment before being discharged into water bodies.

- Advance care planning, especially urban ecological aspects, so that cities have the necessary green spaces, urban expansion is performed in response to environmental values and citizens receive an education that would induce them to appreciate and care for the natural environment.

- Give special consideration to the transport sector in order to promote public transport, the construction of the arteries to avoid congestion and the provision of adequate and well located parking areas.

\section{Sustainable management of water resources}

In 1972, the country had its first National Plan for Water Resources Development. ${ }^{6}$ That Plan Framework was complemented with detailed studies and orchestrated progressively. But for a couple of decades, the national and regional planning of water has not been updated, so it is necessary to do so now, so that the physical and administrative actions required to make efficient use of this resource can be undertaken. Meanwhile, some hydrological imbalances have intensified that must be corrected and the quality of water has deteriorated, especially across the northern coast. In the later context, what deserves particular mention is managing water quality in the basins of the lakes of Valencia and Maracaibo. The water supply of Caracas and other state capitals has become a serious situation. Our island state, the Margarita Island, suffered a permanent deficit of water to meet the influx of tourist population. In the central west there are serious water problems in the states of Lara and Falcon, and problems to meet domestic, agricultural and industrial demands. There is a new water law ${ }^{7}$, but this has not been implemented.

\section{Biodiversity Conservation}

The conservation of biodiversity should be the centerpiece of the strategy to follow in the future in order to achieve ecological sustainability for our development. As stated earlier, the style of development that Venezuela has followed is based on the dominant exploitation of only nonrenewable natural resource has had among other consequences, to be particularly aggressive against the natural physical environment. Becoming aware of this situation is essential to understand that a strategy of biodiversity conservation, truly effective in the medium and long term, includes a modification of our own style

6 'Plan Nacional de Aprovechamiento de los Recursos Hidráulicos (COPLANARH)', Caracas 1972, at <http://www.oas.org/dsd/publications/Unit/oea28s/ch10.htm>.

7 Republica Bolivariana de Venezuela, Ley de Aguas, Caracas 2007. 
of development and the factors that determine it. In other words, the management of biodiversity in Venezuela demands ecological strategies, but also well-studied and implemented economic and social in order to stop the rapid destruction of ecosystems that has taken place.

At the beginning of 2000 the Biological Diversity Act ${ }^{8}$ was enacted and in June of that year, the first report of Venezuela on Biological Diversity was completed. ${ }^{9}$ This provided the fundamental platform for the development of the National Biodiversity Strategy and its Action Plan, the first documents of this kind for Venezuela. This was a step that we must point out. However, this auspicious beginning unfortunately cannot be taken as a point at which biodiversity management was achieved in the framework of the mentioned strategy that could mean a real breakthrough in conservation over the past decade. Two factors have Firstly, the interfered in achieving that objective development.

First, the development style based on oil revenues already mentioned, that before having moderated, has been intensified. The country has never depended economically on from the exploitation of a nonrenewable natural resource o much as it does nowadays. Secondly, the management of the natural heritage for the past 20 years and the actions taken to conserve biological diversityled us to become ranked among the $10 \mathrm{di}$ verse countries in the world. In this aspect, a number of initiatives have being applied, some of which have been more successful than others, as is the case for the establishment of Areas Under Special Administration (ABRAE, in Spanish), but as a whole have failed to stop progressive depletion of biodiversity of the country. Despite these efforts, the information gathered through interviews with experts and the literature reviewed, "indicates an alarming decline in biodiversity in all ecosystems of the country and at all levels of biodiversity: ecosystems, species, and genetics" ${ }^{10}$. Examples of this are:

- Terrestrial ecosystems at risk. An excellent assessment of the state of terrestrial ecosystems in the country has being done, with the available evidence (Rodriguez Rojas - Giraldo Suarez and Hernandez, 2010). The elimination rates of these ecosystems are truly disturbing between 1988 and 2010 in the evergreen forests $(-8.0 \%)$, cloud forests $(-1.0 \%)$ semi-deciduous forest $(-18.7 \%)$, deciduous forests $(-40.7 \%)$, riparian forest $(-6.0 \%)$, spiny shrubs $(-19.4 \%)$, open savannas $(-30.8 \%)$ and savanna shrub and/or forested $(-21.8 \%)$, among others.

- High rates of deforestation. Venezuela continues to have one of the highest rates of deforestation in South America, which in conjunction with forest fires $(109,820$ hectares in 2010, according to the System of National Statistics and Indicators for Environmental Management of the Ministry of the Environment),

8 Republica Bolivariana de Venezuela, Ley sobre Diversidad Biológica, Caracas 2000.

9 Ministerio del Ambiente y de los Recursos Naturales Renovables, Primer Informe de Venezuela sobre Diversidad Biológica, Caracas 2000.

10 Red ARA, Aportes para..., p. 4. 
is the leading cause of habitat destruction and species loss. The deforestation rate is currently estimated at $0.55 \%$ per annum, equivalent to the loss of some 287,000 hectares per year (Mongabay.com, 2011). Deforestation is mainly driven by the expansion of the agricultural frontier, irrational forest exploitation and construction of infrastructure.

- Marine ecosystems at risk. Most coral reefs are threatened by increasing concentrations of sediments from deforestation and onshore oil pollution and other organic waste generated by human settlements and industries. In 1996, there was an extensive coral mortality in the National Park Morrocoy that eliminated about $50 \%$ of the population of existing corals (World Resources Institute, 2011).

- Lacustrine ecosystems at risk. The two largest lake ecosystems, the lakes of Maracaibo and Valencia, are in critical condition and the applied environmental management measures to rescue have them have proven insufficient. The degradation of these important bodies of water is having a negative impact on surro-unding human settlements, agricultural production, and riparian terrestrial and aquatic species.

- While most extensions of national parks and other ABRAE were enacted prior to 1992, constituting a valuable initiative for conservation of biodiversity in situ, as required by the International Convention mentioned above, the management of these areas leaves much to be desired: insufficient or inexistent surveillance; little research within their perimeters which are poorly defined; frequent forest fires take place in many of them. In recent years both have increased: human encroachment to establish humble crops or build houses, and forest fires.

- The Ministry of Environment and NGOs, with the participation of local communities, have implemented programs for the conservation of specific plant and animal species, such as freshwater turtles (hatchlings), sea turtles and the Orinoco crocodile. There are also species whose exploitation is under the control of this Ministry, such as the drool and the chigüire; however, despite these efforts, a significant decline in their populations has been reported. ${ }^{11}$

A particularly commendable effort that has being done regarding Venezuelan biodiversity during the last two decades is the increase in the research of environmental issues taking place especially within our public universities. The Venezuelan congresses of ecology are forums where the results of hundreds of investigations that are moving forward are presented. Without research of this category, it would not be possible to conduct successful programs of biodiversity conservation.

\section{E. Education for Sustainable Development}

In order to successfully confront the serious environmental challenges exposed here, we will require, among many other initiatives, major cultural changes that may be possi-

$11 \quad$ Ibid., p. 11. 
ble through education for sustainable development. Venezuela is in urgent need of a profound transformation of education for the formation of new citizens that will be better prepared to compete professionally in an increasingly globalized world. At the heart of this transformation we must place the education for sustainable development. It refers to an education capable of meeting at least three fundamental aspects. ${ }^{12}$ First: ecological education to educate individuals so that they become fully informed and aware of the functioning of the planet's ecosystem and of the importance of harmonizing lifestyles with the laws of ecology. Second: education for human development, which means an education to prepare individuals to address the social and economic challenges posed by human progress. And third: an education for democratic citizenship, which aims to produce citizens with high ethical principles, able to function within a society that values freedom and is governed by the rule of law.

\section{FINAL REMARKS}

The Venezuelan experience in terms of environmental management can provide a number of lessons that can be useful for other countries.

The first one highlights the importance of considering the predominant style of development, because - as discussed above - this determines the relationship established between society and nature. Investigating every style of development from the perspective of sustainability allows as to find the underlying factors of ecological deterioration and formulate the most effective public policies to facilitete the human progress of the present and the future generation.

The second lesson to be drawn is that the study of the equation: territory + population + socio-political activities, provides the key elements to design the most appropriate environmental management. Therefore, there is not a generic "blueprint" to be utilized for this purpose. This leads to other important conclusions: it is essential to acquire a good knowledge of the characteristics of different natural resources of a country and its articulation ecosystem, as well of the social framework, with its history and culture, its demographic dynamics, psychological and social characteristics, and functioning of political institutions, among other central aspects. And finally, it is imperative to understand the production relations, the prevailing style of the political economy of development and its integration into the globalization process.

The third lesson to be derived is that the general level of socio-political development acquired by the country, in terms of democratic functioning of its institutions, can provide the enabling environment for a successful environmental management. Such management must be the result of the informed and democratic participation of the entire society in order, to achieve sustainability of natural and human capital. In a society ruled by an authoritarian system, it is very difficult to reach the consensus required to achieve this objective.

12 A.J. Gabaldón, Desarollo Sustentable. La Salida de America Latina, Caracas 2006. 


\section{REFERENCES}

Gabaldón A.J., 'De aire puro si vive el hombre: ambiente y desarrollo' in A. Baptista (coord.), Venezuela Siglo XX. Visiones y Testimonios, Tomo 3, Caracas 2001, p. 386.

Gabaldón A.J., Desarrollo Sustentable. La Salida de America Latina, Caracas 2006.

Ministerio del Ambiente y de los Recursos Naturales Renovables, Estrategia Nacional sobre Diversidad Biológica y su Plan de Acción, Caracas 2001.

Ministerio del Ambiente y de los Recursos Naturales Renovables, Primer Informe de Venezuela sobre Diversidad Biológica, Caracas 2000.

Mongabay. Com., News, 2011, at <http: //www.mongabay.com>.

'Plan Nacional de Aprovechamiento de los Recursos Hidráulicos (COPLANARH)', Caracas 1972, at <http://www.oas.org/dsd/publications/Unit/oea28s/ch10.htm>.

Red ARA, Aportes para un diagnostico de la problemática ambiental de Venezuela. La visión de la Red ARA, Caracas 2011.

Republica Bolivariana de Venezuela. Censos Nacionales de Población. Instituto Nacional de Estadísticas, 2006.

Republica Bolivariana de Venezuela, Ley de Gestión Integral de la Basura, Caracas 2010.

Republica Bolivariana de Venezuela, Ley sobre Diversidad Biológica, Caracas 2000.

Republica Bolivariana de Venezuela, Ley de Aguas, Caracas 2007.

República de Venezuela. Comisión del Plan Nacional de Aprovechamiento de los Recursos Hidráulicos, Plan Nacional de Aprovechamiento de los Recursos Hidráulicos, Tomo 1 y 2, Caracas 1972.

Rodríguez J.P., F. Rojas-Suárez, D. Giraldo Hernández, Libro Rojo de los Ecosistemas Terrestres de Venezuela, Caracas 2010.

Sunkel O., N. Gligo (selección), Estilos de Desarrollo y Medio Ambiente en América Latina, Tomo 1-2, México1980.

World Resources Institute, Reefs at risk in the Caribbean, Washington, D.C. 2011.

Arnoldo José GABALDÓN, Civil Engineer, UCAB, 1960. Ms. Stanford University, USA, 1961. Diploma in Development Economics, University of Manchester, UK, 1973. Minister of Public Works from 1974 to 1977. Minister of Environment and Renewable Natural Resources from 1977 to 1979. Member of Congress, Republic of Venezuela, from 1984 to 1994. Chairman of the Presidential Commission for the State Reform (COPRE) 1986-1989. President of the Latin American Centre for Development Administration (CLAD). President of the Administrative Council of the United Nations Program for the Environment 1987-1999. International Consultant in Environment. Honorary Professor at the Simon Bolivar University, where he teaches in the Sustainable Development PhD program. Member of the Academy of Physical, Mathematical and Natural Sciences and the National Academy of Engineering and Habitat. Author of several books. 